\title{
AVALIAÇÃO MULTITEMPORAL DAS PERDAS DE SOLOS NA BACIA DO RIO TAQUARIZINHO-MS
}

\section{MULTITEMPORAL EVALUATION OF SOIL LOSS IN THE TAQUARIZINHO BASIN, MATO GROSSO DO SUL - BRAZIL}

\author{
Antonio Conceição Paranhas Filho', 2 \\ Alberto Pio Fiori ${ }^{3}$ \\ Leonardo Disperati ${ }^{4}$ \\ Cristiane Lucchesi ${ }^{5}$ \\ Alessandro Ciali ${ }^{4}$ \\ Giancarlo Lastoria ${ }^{1}$
}

\begin{abstract}
RESUMO
O ambiente SIG (Sistema de Informações Geográficas) é o ideal para integrar dados, informações e cartas de naturezas diferentes. Por exemplo, dados climáticos e cartas topográficas ou de solos podem ser analisados em conjunto, levando toda a informação para uma base comum, o que permite a sua integração e uso. A Equação Universal de Perdas dos Solos (EUPS ou USLE) é atualmente utilizada, com sucesso, como uma forma para a avaliação da perda dos solos por erosão laminar e foi aplicada para a Bacia do Rio Taquarizinho (ao Sul de Coxim, Mato Grosso do Sul), região que apresentou grandes modificações no tipo de uso e ocupação do solo no período analisado. Neste trabalho são apresentados os parâmetros envolvidos com a USLE, alguns obtidos da digitalização de cartas temáticas e tabelas como de Erosividade das chuvas (R), Erodibilidade do solo (K) ou Uso e Manejo do Solo e Práticas Conservacionistas (CP) e outros, como Comprimento $(L)$ e Declividade de vertentes $(S$,$) obtidos em ambiente SIG, através de dados topográficos. O$ ambiente SIG permitiu a completa integração entre os dados para a obtenção dos parâmetros da USLE e os resultados. Para a Bacia do Rio Taquarizinho a USLE foi aplicada em três diferentes momentos: 1966, 1985 e 1996. Esta aplicação multitemporal mostrou a tendência evolutiva do processo erosivo na região. Para os valores absolutos da taxa de erosão laminar dos solos, de 1966 a 1996, em alguns locais, o desmatamento implicou num aumento da taxa de erosão laminar dos solos em mais de 50 vezes. As perdas médias anuais
\end{abstract}

\footnotetext{
1 Universidade Federal do Mato Grosso do Sul - Departamento de Hidráulica e Transportes - Brasil. <paranhos@nin.ufms.br e lastoria@nin.ufms.br.> 2 Bolsista Capes - Brasília - Brasil.

3 Universidade Federal do Paraná - Departamento de Geologia - Brasil. <fiori@setuva.geologia.ufpr.br.>

4 Università di Siena - Dipartimento di Scienze della Terra - Itália. <pantanal@unisi.it.>

5 Ente Nazionale per L’ambiente e Energie Alternative - Pisa - Itália <clucchesi@altavista.com.>
} 
PARANHOS FILHO, A. C. et al. Avaliação multitemporal das perdas de solos...

de solo por erosão laminar foram representadas por valores médios, para toda a Bacia do Taquarizinho, de 4,44 ton/ha. para 1966, de 5,53 ton/ha. para 1985 e de 8,65 ton/ha. para 1996.

Palavras-chave: erosão, perdas de solo, EUPS, dinâmica ambiental.

\section{ABSTRACT}

The GIS - Geographic Information System environment is ideal for integrating data, information and different kinds of maps. For example, climate data and topographic or soil cover maps can be analyzed together, bringing all the information into a common base, thus permitting integration and use. The Universal Soil Loss Equation (USLE) is currently used successfully as a form of evaluating soil loss via laminar erosion, and it was applied to the Taquarizinho River Basin (to the south of Coxim, Mato Grosso do Sul State), a region which showed great changes in the type of use and occupation of the soil during the period analyzed. In the present work are presented the parameters involved in the USLE, some obtained from the digitalization of thematic maps and tables, such as the Rain Erosive Potential (R), Soil Erodability (K), and Cover and Management of the Soil and Conservation Practices (CP), and others, such as Length (L) and Slope Declivity (S), obtained from the GIS environment, from topographic data. The GIs environment permitted a complete integration between the data used to obtain the USLE parameters, and the results. For the Taquarizinho River Basin, the USLE was applied to three different periods: 1966, 1985 and 1996. This multi-temporal application showed a tendency of evolving erosion in the region. Calculations of the absolute values of rates of laminar erosion of the soils indicate that deforestation has lead to an increase of more than fifty times in such erosion, from 1966 to 1996. The mean annual losses of soil from laminar erosion for the entire Taquarizinho River Basin are calculated to have been 4.44 ton/ha in 1996, 5.53 ton/ha in 1985, and 8.65 ton/ha in 1996.

Key-words: erosion, soil loss, USCLE,

\section{INTRODUÇÃO}

O presente trabalho trata da avaliação das perdas de solos na Bacia do Rio Taquarizinho, região próxima ao Pantanal sul mato-grossense, tendo em vista as modificações ocorridas naquela região, pela influência antrópica, nos últimos 30 anos. Neste tema, a Equação Universal de Perdas de Solo, (ou USLE - Universal Soil Loss Equation), desenvolvida no Departamento de Agricultura dos EUA na década de 1950, constitui-se num importante instrumento de investigação sobre o processo erosivo pois, a partir das características e propriedades dos fatores ambientais responsáveis pelas perdas de solos, permite a compartimentação da paisagem em níveis de instabilidade, possibilitando ações mais efetivas de planejamento ambiental e otimização dos recursos naturais (WISCHMEIER; SMITH, 1958; 1978; WISCHMEIER, 1959; BERTONI et al., 1975; TAVARES, 1986; VITTE, 1997).

\section{LOCALIZAÇÃO E CARACTERÍSTICAS DA ÁREA ANALISADA}

A Bacia do Rio Taquarizinho, localizada próxima à cidade de Rio Verde do Mato Grosso, ao sul da cidade de Coxim (MS - figura 1), foi escolhida por apresentar agricultura intensiva (geralmente monocultura de milho ou soja) e pecuária extensiva, como principal uso dos solos.

\section{A EQUAÇÃO UNIVERSAL DE PERDA DE SOLO - USLE}

A Equação Universal de Perdas de Solo (WISCHMEIER; SMITH, 1978) é um modelo empírico para estimar a perda média anual de solo por erosão laminar, considerando seis fatores independentes:

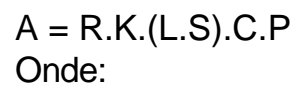

$A=$ perda média anual de solo por unidade de área (ton/ha. ano);

$\mathrm{R}=$ erosividade da chuva;

$\mathrm{K}=$ erodibilidade do solo;

$\mathrm{L}=$ comprimento da vertente;

$\mathrm{S}=$ declividade da vertente;

$\mathrm{C}=$ uso e manejo do solo;

$\mathrm{P}=$ práticas conservacionistas.

\section{GERAÇÃO DO MODELO DIGITAL DO TERRENO}

Sistemas de Informações Geográficas (SIG) são particularmente úteis para tratar dados heterogêneos como cartas topográficas, cartas de solo, de cobertura vegetal, uso da terra, dados meteorológicos etc. Embora de naturezas e escalas diferentes, estas cartas complementadas com outras informações permitem estimar o valor quantitativo do solo erodido, por ano, causado pelo escoamento da água de chuva ao longo das vertentes. 


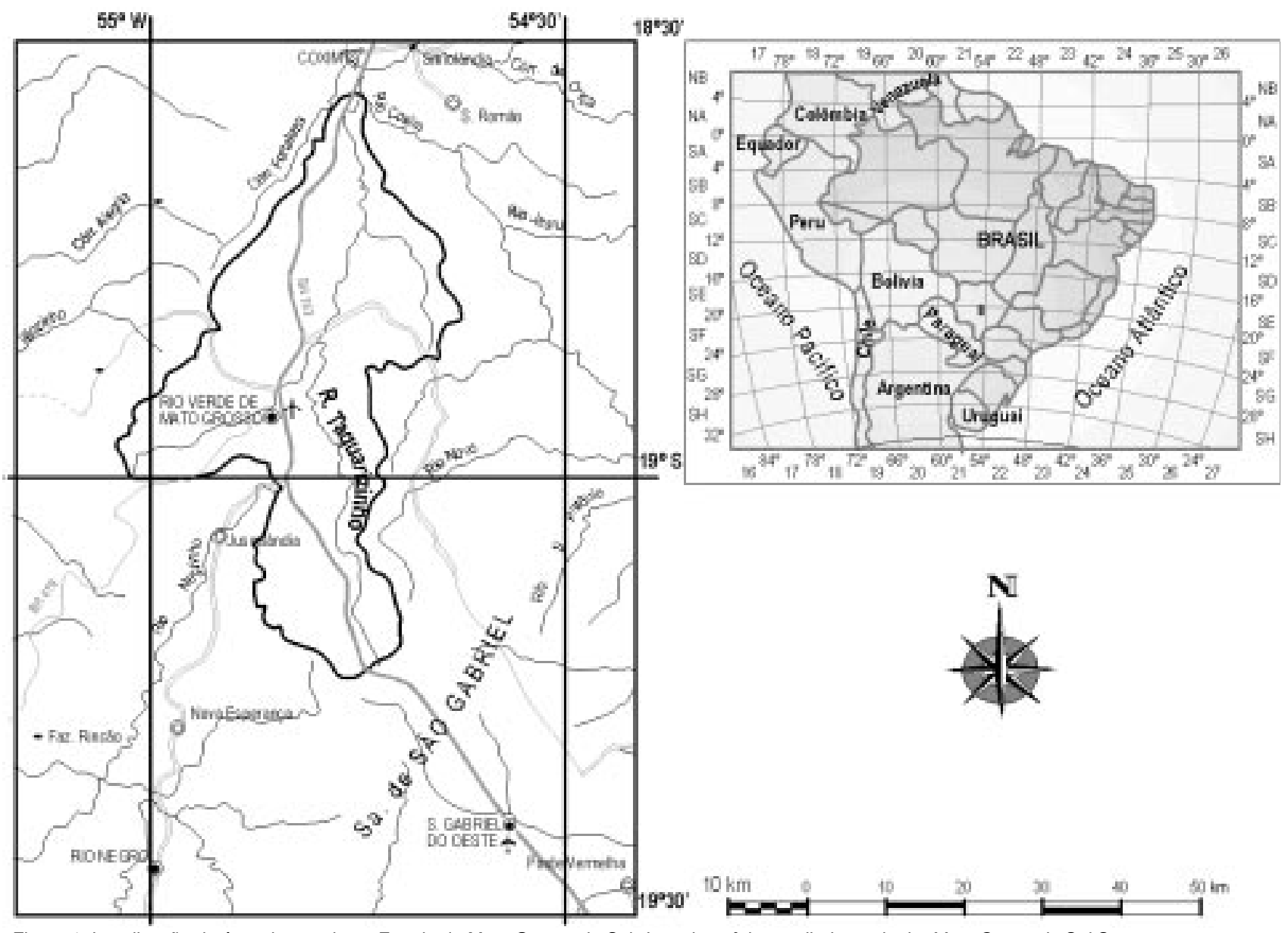

Figura 1: Localização da área de estudo no Estado de Mato Grosso do Sul. Location of the studied area in the Mato Gosso do Sul State.

O primeiro e mais importante passo para a obtenção dos parâmetros da EUPS é a criação de um modelo digital de elevação da área a ser estudada, que servirá como base para a obtenção de vários outros elementos utilizados no cálculo da EUPS. Para a sua geração é necessária a base topográfica, representada por curvas de nível, pontos cotados e hidrografia. Estes dados foram obtidos da digitalização das cartas Coxim e Camapuã (1:250.000, DSG $1982 \mathrm{a} ; \mathrm{b})$. O modelo digital da área estudada está representado na figura 2.

\section{OBTENÇÃO DAS VARIÁVEIS INDEPENDENTES DA USLE}

\section{O FATOR EROSIVIDADE DA CHUVA (R)}

Para a obtenção dos valores de erosividade das chuvas na área de estudo, utilizou-se o mapa de isoerodentes da Bacia do Alto Paraguai elaborado pelo PCBAP (1997). Os valores médios calculados para toda a bacia vão de 6000 a 9500 (MJ mm/ha. h ano), o que representa valores de erosividade elevados, de acordo com as pesquisas efetuadas no estado do Paraná (RUFINO, 1986). A área estudada possui o fator $R$ entre 6810 e $7190 \mathrm{MJmm} / \mathrm{ha}$.h ano. Conforme a classificação do PCBAP (1997), 7000 é o limite entre zonas de erosividade elevada e muito elevada, sendo que o valor médio de R para toda a Bacia do Taquarizinho é 7030 $\mathrm{MJmm} / \mathrm{ha}$.h ano.

\section{FATOR ERODIBILIDADE DOS SOLOS (K)}

A erodibilidade ou a susceptibilidade do solo à erosão pode ser definida como a quantidade de material removido por unidade de área, quando os demais fatores determinantes da erosão são mantidos sob condição padrão (BERTONI et al., 1975; FREIRE et al., 1992). Essa propriedade depende das seguintes características do solo considerado: relação granulométrica entre as classes existentes, textura, grau de agregação, grau de 


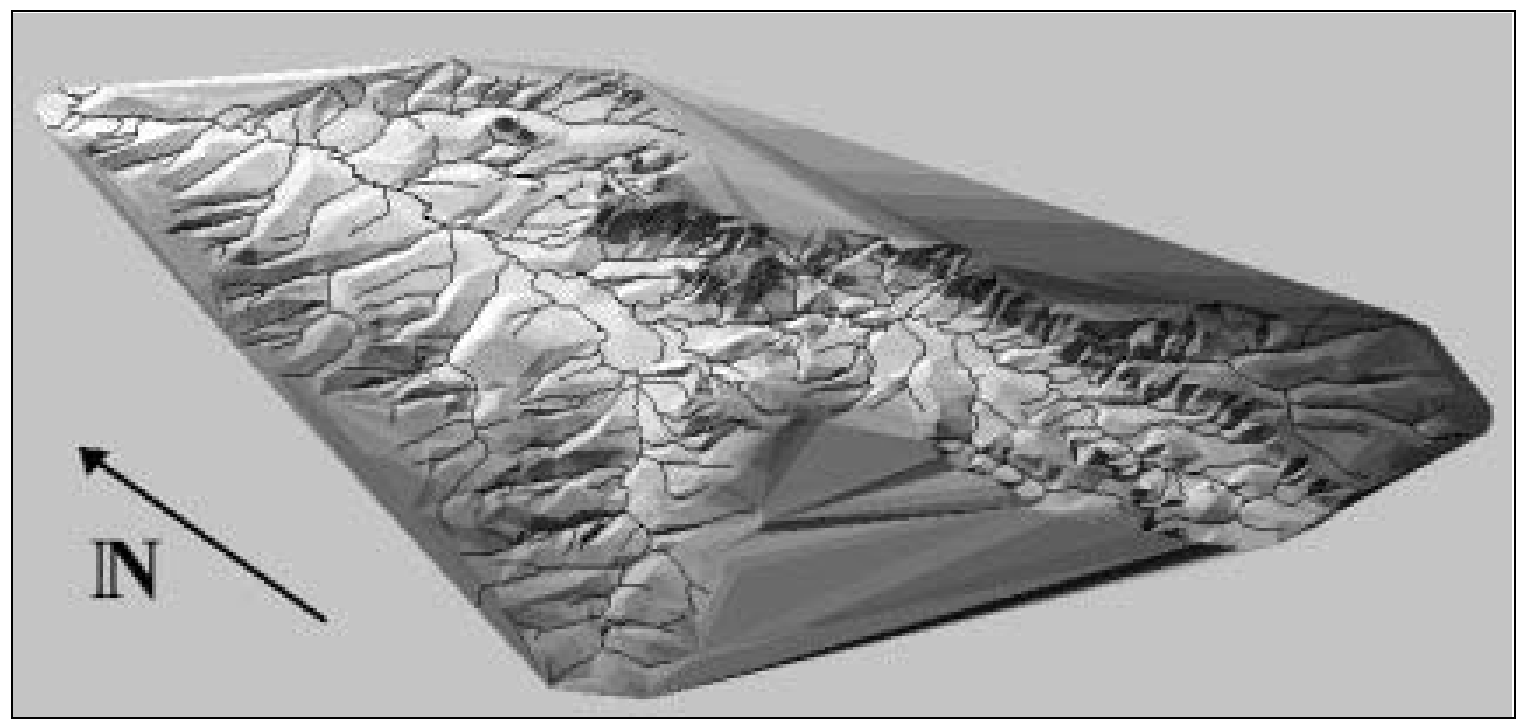

Figura 2: Vista em perspectiva do modelo digital de elevação da bacia do Taquarizinho. Perspective view of the Taquarizinho Basin Digital terrain model.

Tabela 1: Os valores do índice K para os solos da bacia do Taquarizinho (PCBAP, 1997). Taquarizinho Basin soil values for K Index - soil erodibility (PCBAP, 1997).

\begin{tabular}{l|l|l|l}
\hline Solo & Bases & Símbolo & $\mathrm{K}$ \\
\hline Litólicos & a-d-e & R & 0,0050 \\
\hline Areias Quartzosas & a-d & AQ & 0,045 \\
\hline Podzólico vermelho-amarelo & a-d & PV & 0,032 \\
\hline Latossolo vermelho escuro & a-d & LE & 0,016 \\
\hline
\end{tabular}

a - álico, d - distrófico, e - eutrófico. Valores em (ton ha. h/ha. MJ mm)

permeabilidade, teor de matéria orgânica, resistência ao cisalhamento, retenção e transmissão de água. É importante observar que a intensidade da erosão de determinada área pode ser influenciada mais pelo declive, características da chuva, cobertura vegetal e manejo, do que pelas propriedades do solo. Contudo, alguns solos são mais erodíveis que outros, mesmo quando as características morfológicas, a cobertura vegetal, os fatores meteorológicos e as práticas de controle da erosão são iguais. O banco de dados utilizado para o cálculo do fator $\mathrm{K}$ foi obtido a partir de dados de solos do Projeto PCBAP (1997). Os valores do índice K para os tipos de solos da Bacia do Taquarizinho: Solos Litólicos, Areias Quartzosas, Podzólico vermelho-amarelo e Latossolo vermelho escuro, calculados pelo PCBAP (1997), são apresentados na tabela 1.

\section{O FATOR TOPOGRÁFICO (LS)}

O fator topográfico LS é constituído por duas variáveis do relevo que modificam a ação erosiva exercida pela água das chuvas sobre os solos: o comprimento das encostas ( $L$ ) e a declividade das vertentes ( $S$ - figura 3). O aumento do comprimento das encostas acelera a erosão, pois aumenta o volume de água que escoa através de uma seção transversal à vertente e, evidentemente, aumenta a capacidade de remover detritos. Por outro

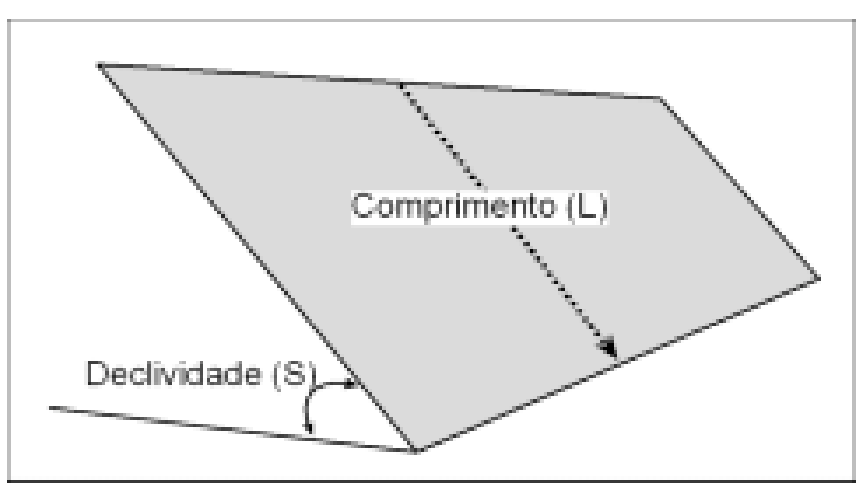

Figura 3: Os parâmetros $L$ e $S$ do Fator Topográfico da EUPS. $L$ and $S$ topographic factor components. 
lado, quanto maior o percurso percorrido pela água sobre a superfície, maior sua possibilidade de infiltrar ou evaporar. Por essa razão, a porcentagem de água escoada em relação à precipitada decresce com o aumento do comprimento de rampa (WISCHMEIER; SMITH, 1958; WISCHMEIER, 1959). Por sua vez, com o aumento da declividade das vertentes, cresce a energia da água e, conseqüentemente, sua capacidade erosiva.

Os parâmetros $L$ e $S$ foram obtidos a partir do modelo digital de elevação da área e representam a relação esperada de perda de solo, por unidade de área, em um declive qualquer em relação às perdas de solo correspondentes a uma parcela unitária de $25 \mathrm{~m}$ de comprimento, com 9\% de declive (WISCHMEIER; SMITH, 1958; WISCHMEIER, 1959).

Para a aplicação prática da EUPS, os parâmetros

$$
L S=\left(\frac{\lambda}{22,13}\right)^{m}\left(0,00654 s^{2}+0,0456 s+0,065\right)
$$

L e S são considerados conjuntamente da seguinte forma (WISCHMEIER; SMITH, 1958; WISCHMEIER, 1959). A carta do fator LS representa, por si só, o Potencial Topográfico de Erosão Hídrica Laminar.

Onde: o valor 22,13 refere-se ao comprimento do talhão-padrão; "l" é o comprimento da vertente e "s" a declividade da vertente em percentagem (obtidos da carta de declividade em percentual).

O valor de $m$ é dependente da declividade das vertentes. Ele foi obtido empiricamente, com base nas informações da carta de declividade do terreno e de acordo com Mills et al. (1985):

$$
\begin{aligned}
& \mathrm{m}=0,5 \text { em declividade }>5 \% \\
& \mathrm{~m}=0,4 \text { em declividade }<5 \% \text { e }>3 \% \\
& \mathrm{~m}=0,3 \text { em declividade }<3 \% \text { e }>1 \% \\
& \mathrm{~m}=0,2 \text { em declividade }<1 \%
\end{aligned}
$$

\section{FATORES DE USO E MANEJO DO SOLO (C) E PRÁTICAS CONSERVACIONISTAS (P)}

O fator $P$ representa a razão entre a perda de solo que ocorre em dada prática conservacionista e aquela que ocorre para cultivos no sentido do declive máximo do terreno (plantio morro abaixo). O fator $\mathrm{P}$ só é aplicado em áreas cuja cobertura seja de cultivo. Em outras palavras, este fator é um ponderador do fator $\mathrm{C}$ em situações especiais de uso e manejo do solo. As práticas mais comuns para culturas anuais são: plantio em contorno, plantio em faixas de contorno, terraceamento e alternância de capinas.

Os fatores $C$ e $P$ são tratados individualmente quando se buscam formas mais adequadas de produção agrícola conservacionista. Entretanto, segundo Stein et al. (1987), as variáveis C e P são de tal forma inter-relacionadas que não se pode analisá-las individualmente. Aqueles autores trataram em conjunto os fatores $\mathrm{C}$ e $\mathrm{P}$, elaborando uma tabela de uso geral com os valores de $\mathrm{CP}$ em função de diferentes grupos e categorias de vegetação.

$\mathrm{Na}$ área examinada, o único tipo de prática conservacionista agrícola encontrada é o plantio em curvas de nível (terraceamento).

Para o cálculo do fator CP na área de estudo, pelas finalidades deste trabalho, a tabela elaborada por Stein et al. (1987) foi modificada (tabela 2) em função das características dos dados de uso do solo observados. As cartas de uso dos solos para a região foram obtidas de dois modos. Para 1966, utilizaram-se as informações sobre o uso do solo contidas nas cartas Camapuã e Coxim (DSG, 1982a, b). Para 1985 e 1996, as cartas de uso do solo foram obtidas de Paranhos Filho (2000), que adaptou a legenda de uso do solo do Projeto Corine (HEYMANN et al., 1994) à região.

Tabela 2: Valores do fator CP para cada classe de uso do solo na área da Bacia do Taquarizinho (modificada de Stein et al., 1987). Taquarizinho Basin values for CP, modified from Stein et al., 1987.

\begin{tabular}{c|l|l}
\hline Classe CORINE & descrição & $\mathbf{C P}$ \\
\hline 1.1 & Área urbanizada & $\mathbf{0 , 0 0}$ \\
\hline 2.1 .1 & Áreas aráveis, (culturas sazonais) & 0,20 \\
\hline 2.3 .1 & Pastagem, antropizado & 0,01 \\
\hline 3.1 .1 & Floresta permanente, cerradão & 0,00004 \\
\hline 3.2 .1 & Pradarias & 0,01 \\
\hline 3.2 .2 & Cerrado & 0,0007 \\
\hline 3.3 .2 & Áreas em que aflora o substrato & 0,00 \\
\hline 3.3 .3 & Áreas de vegetação rala & 0,25 \\
\hline 3.3 .4 & Áreas queimadas & 0,01 \\
\hline 4.1 .1 & Áreas úmidas & 0,00 \\
\hline 5.1 .1 & Cursos de água - rios & 0,00 \\
\hline 5.1 .2 & Corpos de água - lagos & 0,00 \\
\hline
\end{tabular}




\section{PERDA MÉDIA ANUAL DE SOLO NA BACIA DO TAQUARIZINHO}

Os resultados obtidos com a aplicação da EUPS podem ser visualizados como cartas de perda por erosão dos solos em toneladas por hectare ano ou Carta do Fator A. Para o ano de 1966, esta carta apresenta os índices mais altos de erosão laminar concentrados em três áreas. A comparação desta carta com a carta topográfica e com a carta geomorfológica (RADAMBRASIL, 1982) mostra que essas áreas são representadas por superfícies planas, indicando não ser o gradiente topográfico a principal causa de erosão. A comparação com a carta geológica (RADAMBRASIL, 1982) mostra que estas áreas distribuem-se sobre três unidades distintas: Formações Furnas; Ponta Grossa e Coberturas Detrito-Lateríticas; indicando não haver relação direta entre o índice de erosão e o tipo do substrato geológico.

A comparação da carta da taxa de erosão com a de solos (RADAMBRASIL, 1982) evidencia que os valores mais altos do Fator A ocorrem tanto sobre os Latossolos da Chapada de São Gabriel (extremo sul da área do Taquarizinho), quanto sobre os latossolos, pdzóis e outros tipos mais a norte. Também indicando não haver relação direta entre o índice de erosão com o tipo de solo. Já a comparação da carta do Fator A com a de uso dos solos para o ano de 1966 (figura 4) coloca em evidência que valores elevados de $\mathrm{A}$ (acima de 20 ton/ha.ano) aparecem em áreas agrícolas, indicando que o uso dos solos é o principal fator determinante nos valores de $A$ para a Bacia do Taquarizinho.

Para o ano de 1985, altos valores do Fator A aparecem distribuídos por toda a área, como conseqüência do intenso desmatamento ocorrido em toda a região e que pode ser avaliado comparando-se as cartas de uso dos solos de 1966, quando cerrado e floresta somavam cerca de $89 \%$ da superfície da bacia do Taquarizinho, com a carta de 1985, quando este valor caiu para $30 \%$ da superfície. No mesmo período, as áreas ocupadas por atividades agropecuárias passaram de $9 \%$ para mais de $70 \%$. As áreas desmatadas em regiões de topografia mais acentuada começaram a apresentar também maiores valores de erosão laminar dos solos. As áreas agrícolas, principalmente ao sul da bacia, continuaram apresentando al- tos valores para o Fator A, ocupando uma superfície total um pouco maior em 1985 em relação a 1966.

Na carta de perdas por erosão dos solos para o ano de 1996 (figura 5), os altos valores do Fator A aparecem distribuídos por toda a carta. Além do desmatamento, observado na comparação dos valores deste tipo de cobertura de 1966, com os de 1996, em 1996 aparecem mais áreas descobertas (sem vegetação ou de queimadas), nas quais verifica-se um aumento do valor de A (figura 5). Nos locais em que o cerrado voltou a crescer, o valor de A diminuiu. As áreas agrícolas (principalmente ao sul da área) também apresentam valores mais elevados do índice de erosão laminar em 1996.

Para a Bacia do Taquarizinho, com cerca de 148.084 ha, o valor médio da erosão laminar (A) obtido da média ponderada dos valores da células que compõem o seu grid, pode ser visualizado na tabela 3. Estes valores de erosão praticamente dobraram no período de 30 anos estudado.

Para facilitar a visualização e a compreensão das tendências das áreas em relação à erosão, foi calculada ainda a "Razão de Erosão" (RE), que representa a diferença entre o ano em análise e o ano inicial, dividida pelo ano inicial. Abaixo, é mostrado um caso utilizando-se a relação entre 1966 e 1985 como exemplo:

$$
\text { RazãodeErosão }=\frac{A_{1996}-A_{1985}}{A_{1985}}
$$

Desta forma, resultados iguais a zero significam que não houve alterações na taxa de erosão da área em questão. Enquanto valores positivos indicam aumento da taxa de erosão, valores negativos indicam diminuição desta taxa.

Para o período entre 1966 e 1996, os resultados também mostram um aumento maior do que 50 vezes na taxa de erosão que, pontualmente, chega a 200 vezes. Resultado semelhante ao período de 1966-1985, pois corresponde a áreas de desmatamento ou queimadas, onde a mata foi cortada e substituída por pastagens e agricultura. Porém em algumas áreas o ressurgimento do cerrado implicou em não aumento da taxa de erosão ou mesmo diminuição.

Tabela 3: Valores médios totais de erosão laminar para a Bacia do Taquarizinho, em 1966, 1985 e 1996. Total mean values for Taquarizinho Basin laminar soil erosion, in 1966, 1985 e 1996.

\begin{tabular}{c|c|c}
\hline ano & Valor médio de A (ton/ha. ano) & Erosão Laminar Média Total (ton/ano) \\
\hline 1966 & 4,44 & $657.937,95$ \\
\hline 1985 & 5,53 & $818.165,02$ \\
\hline 1996 & 8,65 & $1.280 .335,70$ \\
\hline
\end{tabular}




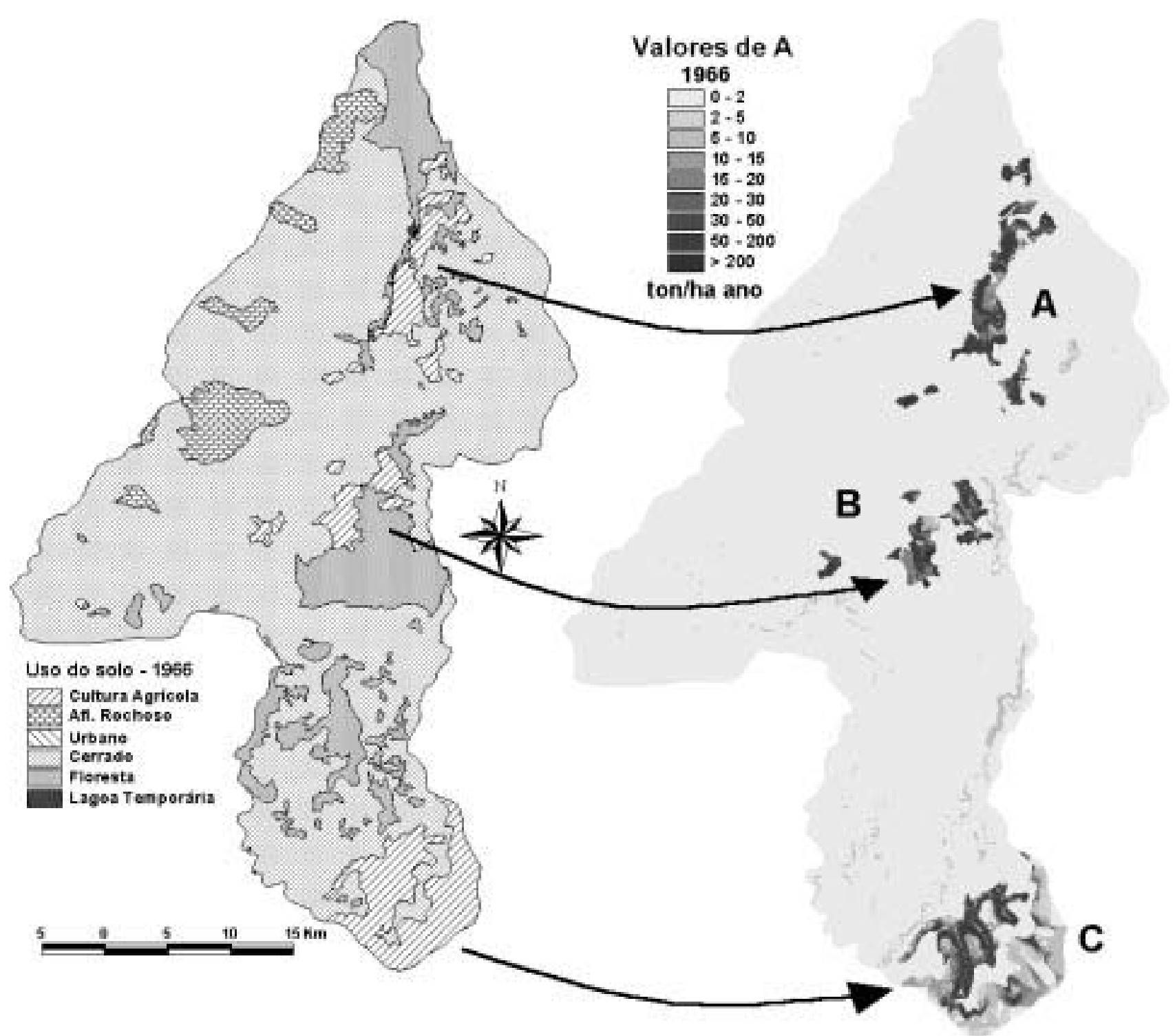

Figura 4: Comparação da carta com Valores de A (ton/ha. ano), perda por erosão laminar e a carta de uso dos solos, para a Bacia do Rio Taquarizinho referente ao ano de 1966. Comparison between the A values chart (ton/ha. year) with land use map, both Taquarizinho Basin 1966 data.

O cálculo da razão de erosão entre 1985 e 1996, em relação a 1966, mostra várias áreas onde houve a diminuição no valor de A em 1996, coincidindo com um aumento nas áreas de mata e cerrado em 1996 em relação a 1985.

A figura 6 mostra que em 1966, mais de $86 \%$ da superfície era coberta por matas e cerrados e as áreas agrícolas representavam apenas cerca de $9 \%$. Em 1985, as áreas naturais representavam menos de $28 \%$ e apro- ximadamente $33 \%$ em 1996. As áreas ocupadas pelas atividades agropecuárias diminuíram de 1985 a 1996, embora o percentual de áreas degradadas tenha aumentado de 1,2\%, em 1985 a 3,9\%, em 1996.

Houve uma diminuição na área das terras utilizadas para a agropecuária de 1985 (cerca de $71 \%$ da superfície ou 104.686 ha) a 1996 (cerca de $63 \%$ da superfície ou 92.990 ha - uma diferença de 11.676 ha), com uma correspondente queda nos valores de A neste período. 


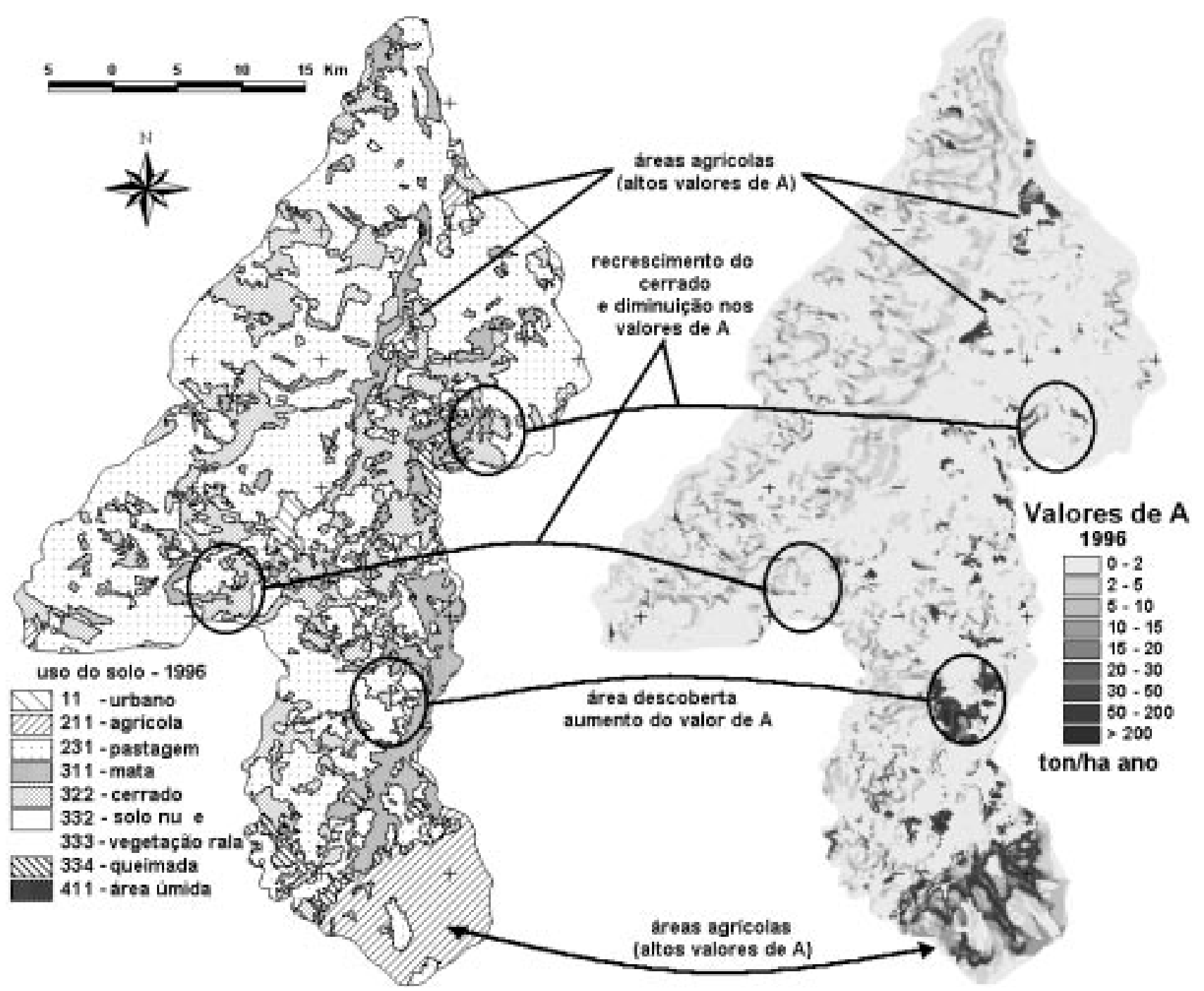

Figura 5: Comparação da carta com Valores de A (ton/ha. ano), perda por erosão laminar e a carta de Uso dos solos, para a Bacia do Rio Taquarizinho, em 1996. Comparison between the A value chart and the land use map, both in 1996, Taquarizinho Basin area.

\section{CONCLUSÕES}

As mudanças observadas no tipo de uso do solo para a bacia do Taquarizinho são grandes. Tomando como referência o ano base de 1966, mais de $86 \%$ da superfície (127.693 ha) era ocupada por áreas naturais, sendo que destas, $14,47 \%$ correspondiam a florestas e $71,76 \%$ ao cerrado. Já em 1985, as superfícies naturais mostram uma grande diminuição em área, passando a menos de $28 \%$ (41.167 ha) do total da área estudada. No ano de 1996, essas áreas mostram uma ligeira recuperação, quando passam a ocupar cerca de $33 \%$ da área (48.310 ha).
Concomitantemente, as áreas ocupadas por atividades agropecuárias, que em 1966 representavam apenas cerca de $9 \%$ do total (13.230 ha), passaram a ocupar, em 1985, mais de $70 \%$ da superfície (104.685 ha), num impressionante avanço dessas atividades à custa do desmantelamento de áreas naturais. Esse valor, porém, caiu para cerca de $63 \%$ no ano de 1996 (92.990 ha).

A diminuição da área utilizada para as atividades agropecuárias no período entre 1985 e 1996 parece estar associada a evasão rural, pois a área urbana cresceu de 0,13\% em 1985 para 0,62\%, em 1996 (um aumento de 5 vezes em 11 anos), ao mesmo tempo em que a área 


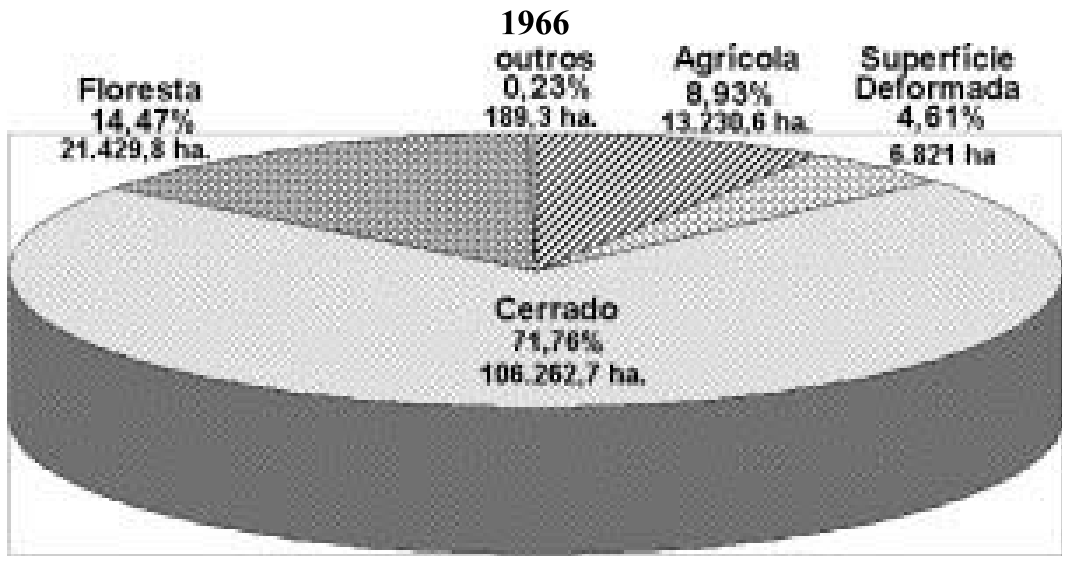

\section{5}

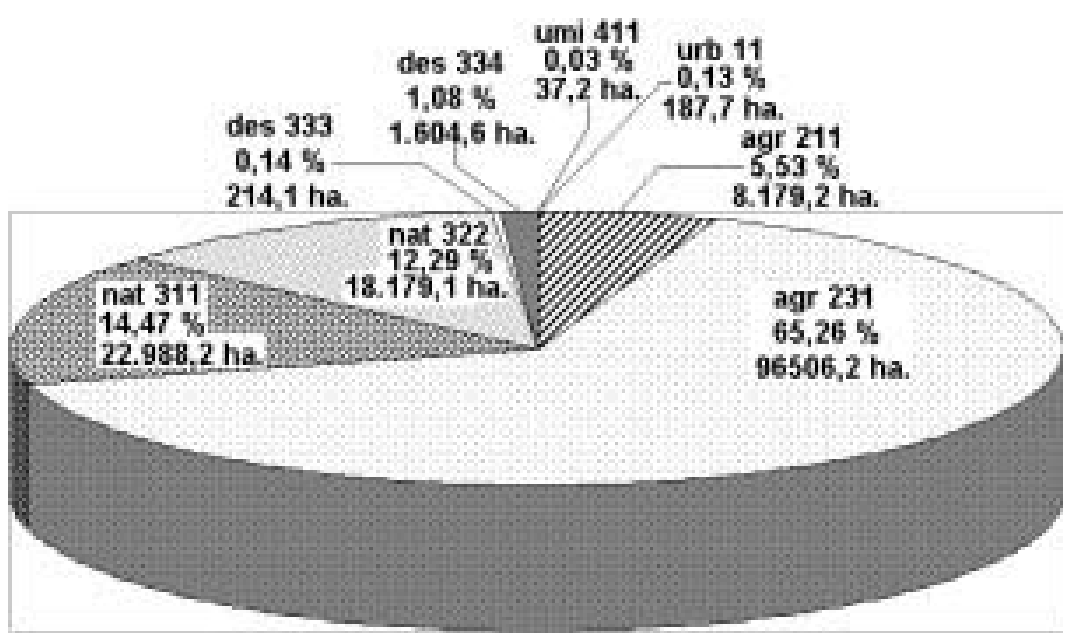

Legenda:

11 - urb - áreas urbanas

211 - agr - áreas agrícolas

231 - agr - pastagens e agropecuária

311 - nat - florestas

322 - nat - cerrados

332 - des - solo nu

333 - des - áreas de vegetação rala

334 - des - queimadas

411 - umi - áreas úmidas

\section{6}

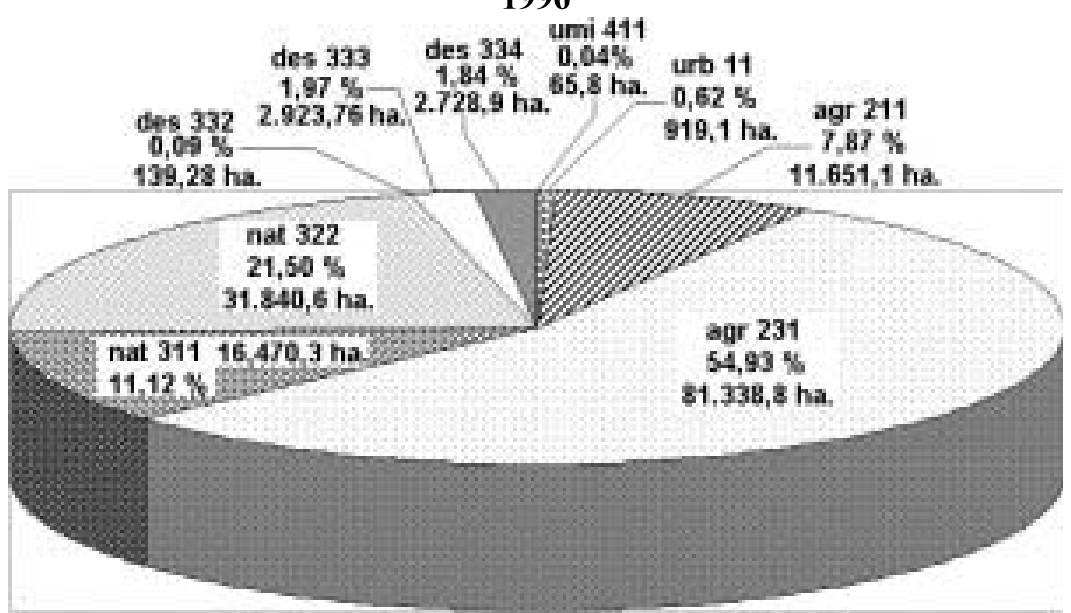

Figura 6: Diferentes tipos de uso e cobertura dos solos para os anos de 1966, 1985 e 1996, ocorridas na Bacia do Taquarizinho. Land Cover Comparative Graphics for 1966, 1985 e 1996, showing the changes at Taquarizinho Basin. 
ocupada pelas atividades agropecuárias caiu de 70\% (em 1985) para 63\% (em 1996).

As perdas médias anuais de solo por erosão laminar, calculadas através da Equação Universal de Perdas dos Solos, são representadas por valores médios, para toda a Bacia do Taquarizinho, de 4,44 ton/ha para o ano de 1966, 5,53 ton/ha. para o ano de $1985 \mathrm{e}$ 8,65 ton/ha, para o ano de 1996 . O valor da erosão média laminar de 1996 é praticamente o dobro daquela que ocorria no ano de 1966, antes da rápida ocupação da área por atividades agropecuárias. O total erodido em 1966 foi de 657.938 toneladas enquanto que em 1996 foram erodidas 1.280 .336 toneladas em toda a bacia.

Em 1966, os valores de A em geral, não ultrapassavam 2 ton/ha.ano, concentrados em apenas três zonas agrícolas específicas. Já em 1985, bem como 1996, com o aumento do uso da terra, principalmente pela agri- cultura intensiva (principalmente milho e soja), verificouse um aumento nos valores de A (em alguns casos, da ordem de 50 vezes, ou mais), com ampliação de sua distribuição por toda a área de estudo.

\section{AGRADECIMENTOS}

O presente trabalho foi desenvolvido no contexto do projeto Geo-environmental dynamics of PantanalChaco: multitemporal study and previsional modeling, financiado pela União Européia (EU contract : ERBIC18CT960073).

No período de janeiro a julho de 1999 o autor principal contou com Bolsa de Doutorado Sanduíche da Capes, Brasília.

Agradecimentos ainda ao Prof. Dr. Kennedy Francis Roche (DHT - CCET - UFMS) pela tradução e confecção do abstract.

\section{REFERÊNCIAS}

BERTONI, J.; LOMBARDI NETO, F.; BENATTI JUNIOR, R. Equação de perdas do solo. Boletim Técnico do Instituto Agronômico do Estado de São Paulo. Campinas, n. 21, p. 125, 1975.

DSG - Diretoria do Serviço Geográfico Brasileiro. Carta Camapuã. Folha SE.21-Z-D (MIR-445). Escala 1:250.000. Ministério do Exército - Região Centro-Oeste do Brasil- Diretoria do Serviço Geográfico Brasileiro. Carta, 1982a.

DSG - Diretoria do Serviço Geográfico Brasileiro. Carta Coxim. Folha SE.21-Z-B (MIR-432). Escala 1:250.000. Ministério do Exército - Região Centro-Oeste do Brasil- Diretoria do Serviço Geográfico Brasileiro. Carta, 1982b.

FREIRE, O.; GODOY, M. C. T. F.; CARVALHO, W. A. Erodibilidade de alguns solos do oeste do Estado de São Paulo. Revista de Geografia, São Paulo, n. 11, p. 77-87, 1992.

HEYMANN, Y.; STEENMANS, C.; CROISILLE, G.; BOSSARD, M. Corine Land Cover Project - Technical Guide. European Commission, Directorate General Environment, Nuclear Safety and Civil Protection, ECSC-EEC-EAEC, BrusselsLuxembourg, 1994. $136 \mathrm{p}$.

MILLS, W. B.; PORCELLA, D. B.; UNGS, M. J.; GHERINI, K. V.; SUMMERS, K. V.; LINGFUNG MOK, G. L.; RUPP, G. L.; BOWIE, G. L.; HAITH, D. A. Water Quality Assesment: A Screening Procedure for toxic and Conventional Polltants in surface and Ground Water. Report Volume I - Environmental Research Laboratory. United States Department of Commerce, NTIS - National Technical Information Service. September 1985. 314 p.

PARANHOS FILHO, A. C. Análise Geo-ambiental Multitemporal: o caso de estudo de Coxim e da Bacia do Taquarizinho (MS
- Brasil). 2000, 213 p. Tese (Doutorado em Geologia) - Universidade Federal do Paraná.

PCBAP - Plano de Conservação da Bacia do Alto Paraguai. Ministério do Meio Ambiente, dos Recursos Hídricos e da Amazônia Legal. In: Plano de Conservação da Bacia do Alto Paraguai. Volumes: I. 73 p. II, Tomos I e II-A, 334 p. e 386 p. Programa Nacional do Meio Ambiente - PNMA. 1997. RADAMBRASIL. Ministério das Minas e Energia. Secretaria Geral. Folha SE 21 Corumbá e parte da Folha SE. 20: geologia, geomorfologia, pedologia, vegetação e uso potencial da terra. Levantamento de Recursos Naturais, 27. Rio de Janeiro, 1982b. 452p. il. 5 mapas.

RUFINO, R. L. Avaliação do potencial erosivo da chuva para o Estado do Paraná: Segunda aproximação. Revista Brasileira Ci. Solo, v. 10, p. 279-281, 1986.

STEIN, D. P.; DONZELLI, P. L.; GIMENEZ, F. A.; PONÇANO, E. L.; LOMBARDI NETO, F. Potencial de Erosão Laminar, Natural e Antrópica na Bacia do Peixe-Paranapanema. In: SIMPÓSIO NACIONAL DE CONTROLE DE EROSÃO, 4., 1987, Marília. Anais... Marília: ABGE/DAEE, 1987.

TAVARES, A. C. A Erosão dos Solos no Contexto da Análise Ambiental: O Exemplo do Alto Curso do Rio São José dos Dourados. SP, 1986, 300 p. Tese (Doutoramento) - FFLCH Universidade de São Paulo.

VITTE, A. C. Metodologia para cálculo de perdas de solo em bacias de drenagem. Boletim Paranaense de Geociências, Paraná, n. 45, p. 45-65, 1997.

WISCHMEIER, W. H. A Rainfall Erosion Index for a Universal Soil Loss Equation. Soil Sc. Soc. Am. Proc., Madison, v. 23, n. 2, p. 246-249, 1959. 
PARANHOS FILHO, A. C. et al. Avaliação multitemporal das perdas de solos...

WISCHMEIER, W. H.; SMITH, D. D. Rainfall Energy and its Relationships to Soil Loss. Amer. Geoph. Union, Transactions, Washington, v. 39, n. 2, p.285-291, 1958.
WISCHMEIER, W. H.; SMITH, D. D. Predicting rainfall erosion losses. A guide to conservation planning. USDA Handbook, Washington, n. 537, 57 p., 1978. 